
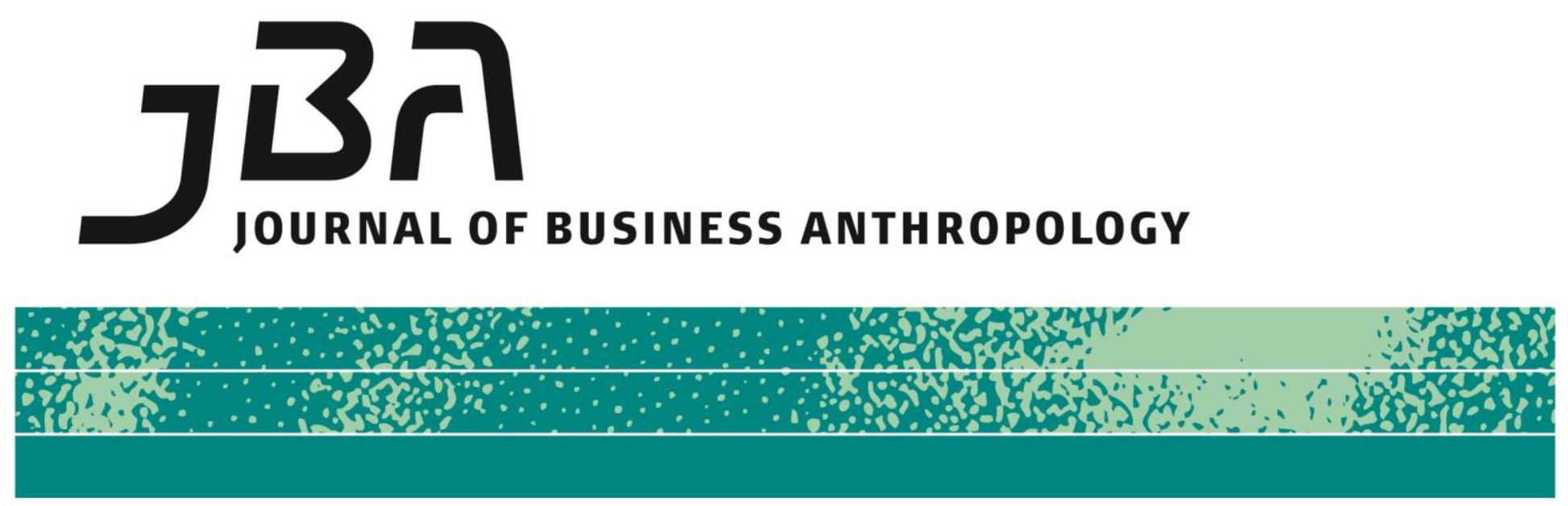

\title{
Opinions: Ethnographic Methods in the Study of Business
}

Elizabeth K. Briody, Gary Alan Fine, Katarina Graffman, Stephanie A. Krawinkler, Maryann McCabe, Patricia Sunderland and Rita Denny

For this issue of the Journal of Business Anthropology, I approached a number of people who have conducted research in, with, on, or for business organizations of one sort or another and asked them to reflect upon their ethnographic experiences. What follows is a series of essays by scholars and practitioners - many of them extremely experienced, but one at the beginning of her career - who between them have provided us with a collation of exemplary practices and insights. It isn't just restaurant kitchens and home cooking that provide 'food for thought', but cruise ships, art museums, General Motors, and an Austrian electrical company. Bon appetit! 


\section{Collaboration and Anthropology in Corporate Work}

Elizabeth K. Briody, Cultural Keys, LLC

As an anthropologist working at General Motors (GM) R\&D (1985-2009), I was used to questions from employees, friends, academics, and the media about my role and methods. Yet, when Brian Moeran asked me to write about ethnographic methods in the study of business, I felt challenged. My basic toolkit was common to most cultural anthropologists - content analysis of ethnographic field data - although my role as an applied researcher was also to develop recommendations, and sometimes interventions, to improve organizational effectiveness. Upon reflection, I decided that those interested in business anthropology might find the evolution of how I worked (my approach), and how I analyzed my project data (thematically), relevant to their own research.

In this opinion piece, I discuss a convergence over time between my research approach and the analysis of my research data at GM. This convergence represents an important transition from independence to collaboration as I changed from being an academically-trained anthropologist to an applied anthropologist in a business setting. It also reflects the construction of a body of cultural knowledge about the corporation in the form of cultural themes. Simultaneously, I show that this same transition to a collaborative partnership paradigm was occurring within GM. I end by arguing that collaboration is generally a more productive work practice than independent efforts by individuals, that collaboration has a greater potential to improve organizational effectiveness, and that anthropologists are well suited to leading and facilitating collaborative projects.

\section{The transition from sole researcher to team researcher}

Anthropologists often work alone in the field and alone during analysis and writing, though they may consult with others (their study participants, colleagues, and/or professors, for example). I, too, was a lone field researcher when I began working at GM. It was up to me to develop a proposal, review it with my supervisor as well as with the management of the particular unit that might approve the work, establish rapport with study participants, gather and make sense of studyparticipant data, write up my findings and recommendations, and handoff the final report. My communication with the management of the sponsoring unit was limited and occurred mostly when the project was ending. While it was the case that I was the only anthropologist at GM R\&D, GM colleagues from other disciplines also worked independently. Thus, the pattern of working largely alone at GM R\&D was common at that time. 
However, I soon began a multi-year collaboration with an academic anthropologist and her students at a nearby university. Our relationship with our GM management sponsors became regular and direct; there was keen interest in what we were learning and recommending. I built on this approach in subsequent projects and began developing deeper relationships with sponsoring-unit leaders. For example, I became more visible as I set out to explore the operations of two different product programs and served as both researcher and consultant to them. I offered workshops to help them explore interventions to deal with their cross-cultural problems. My new role was a reflection, in part, of the changing view of research at GM. Researchers were charged to become increasingly applied in their focus, to identify committed sponsors for each new research project, and to work with those sponsors closely to address key issues. At this time, I also expanded my relationships with anthropologists at other universities and in my professional associations.

In the early 2000s, my work pattern changed again. I supervised a graduate student intern who ultimately became a GM contract employee. Together we began building a team of researchers by leveraging our contacts. Our team had regular interactions - both informal updates and formal presentations - with our management sponsors. GM's external partners also sought us out.

Aside from the obvious benefits of having a wider variety of experts on our team, and more of them, this kind of teamwork also reinforced the value of developing strong relationships with the leadership of the sponsoring units. When those linkages were robust, it was possible to work directly with them to frame and conduct the research. These projects were more relevant and our recommendations were frequently implemented. In one of our last projects, the sponsoring leaders engaged in what anthropologists call community-based participatory research. Their questions and insights led to collaboration on ten tools or interventions. In contrast to my earlier hand-off approach, working directly with the sponsoring leadership allowed our research team to become an effective part of a far bigger team effort within the corporation.

\section{Compiling a thematic understanding of GM culture}

In the mid-1980s, much of the popular business press focused on corporate culture, describing it in ways that made little sense to me (for instance, strong or weak cultures). In one of my first projects, I identified a pattern of blame and blame avoidance. I was able to operationalize the theme of blaming and found that it helped me make sense of seeminglydisparate perspectives and behaviors. Blaming was expressed in statements made by manufacturing workers who were frustrated by poor product quality. Employees blamed those upstream from them in the assembly process and those on the previous shift, not their own shift. The 
content of the blaming statements reflected GM's rocky transition from production quotas at any cost, to improvements in quality while maintaining efficiency. This thematic approach both resonated within GM and was easy to explain. It became an important analytical component in future projects.

Historically, GM's culture has been characterized by autonomy (defined as acting and developing independently of the whole) and its allied theme of individualism. Autonomy was evident in GM's distinctive, differentiated, and decentralized operations. Indeed, GM was formed in 1908 from the consolidation of several different car companies that were linked together through committees and financial controls. Each GM unit or division had its own assumptions, expectations, and values. Work practices and processes were 'home grown' by these individual units, rather than centrally developed and disseminated. Terms and phrases such as 'silos,' 'functional chimneys,' 'turf,' 'not invented here,' and 'my way or the highway!' reflect the themes of independence, self-reliance, and ethnocentrism and continue to be part of the firm's vernacular today.

In all of the projects I worked on while at GM, autonomy always had an effect on the ways in which employees understood their roles, how work was conducted, and the overall course of organizational events. However, other cultural themes emerged from my project data as well.

\begin{tabular}{|c|c|c|c|}
\hline $\begin{array}{l}\text { Data } \\
\text { Collection } \\
\text { Year(s) }\end{array}$ & Project & Cultural Themes & Focus \\
\hline 1986 & $\begin{array}{l}\text { Truck Assembly } \\
\text { Plant }\end{array}$ & Blaming & Quality \\
\hline $1986-88$ & Expatriates & Parochialism & $\begin{array}{l}\text { Adaptation and } \\
\text { Repatriation }\end{array}$ \\
\hline 1988-89 & Reorganization & Autonomy & $\begin{array}{l}\text { Organizational } \\
\text { Status }\end{array}$ \\
\hline 1990-91 & Downsizing & $\begin{array}{l}\text { Career } \\
\text { Advancement }\end{array}$ & Job Mobility \\
\hline $1993-94$ & $\begin{array}{l}\text { Vehicle } \\
\text { Development } \\
\text { Process }\end{array}$ & Ambiguity & $\begin{array}{l}\text { Commonality and } \\
\text { Differences }\end{array}$ \\
\hline 1996-98 & $\begin{array}{l}\text { Global Product } \\
\text { Program }\end{array}$ & Differentiation & $\begin{array}{l}\text { Cross-Unit } \\
\text { Integration }\end{array}$ \\
\hline $1998-2000$ & Strategic Alliances & Authority & Decision Making \\
\hline 2001-03 & R\&D Partnerships & Reciprocity & Effectiveness \\
\hline $2002-07$ & $\begin{array}{l}\text { Researcher } \\
\text { Workspace }\end{array}$ & Productivity & $\begin{array}{l}\text { Workspace } \\
\text { Requirements }\end{array}$ \\
\hline $2002-07$ & $\begin{array}{l}\text { New Vehicle } \\
\text { Assembly Plant }\end{array}$ & Collaboration & Ideal Plant Culture \\
\hline 2007-08 & Integrated Health & $\begin{array}{l}\text { Health Care } \\
\text { Fragmentation }\end{array}$ & Customer Views \\
\hline
\end{tabular}

Table: Key Cultural Themes and Focus of Selected GM Projects by Data Collection Year(s) 
Morris E. Opler has argued that a longitudinal examination of cultural themes often reveals changes in culture. Until I completed an analysis of my research projects by theme and year, I was unaware of the transformation playing out in my own data. Cultural conflict and ethnocentric behavior emerged during the first fifteen years of my GM career. For example, cultural conflict appeared in the parochialism of GM's domestic units in accepting, and later promoting, returning GM expatriates. In another project, a global vehicle program had insufficient authority to be successful. Ethnocentric behavior combined with little cohesion among the participating GM units resulted in decision-making ambiguity, program delays, cost overruns, and ultimately failure.

In the most recent projects, conflict and ethnocentrism lessened and were overshadowed by an increasingly-cooperative spirit. We found a desire for building and maintaining strong, healthy working relationships both within GM and beyond. Themes of reciprocity and collaboration featured prominently. For example, when GM R\&D provided funding to professors at several universities, it never anticipated that reciprocity would play a key role in maintaining those long-term relationships so that the projects would be successful. Similarly, in the ideal plant culture project, we discovered a consensus view of a desired future culture among hourly, salaried, and executive employees. They repeatedly expressed a unified vision and a cooperative orientation to manufacturing work.

\section{Validating a cultural shift in GM's cultural evolution}

W. Lloyd Warner emphasized cultural explanation within a broader societal context. In particular, he examined the relationship between external forces and community and organizational activity. In that same spirit, I asked myself: to what extent has GM's autonomous culture been tempered over its 105-year history? With my own career as a case in point, I saw that my work evolved from the sole researcher model to one that was inclusive of other researchers and employees at all levels including senior leaders. In addition, I discovered that there had been a transformation in the cultural themes from my research projects toward an emphasis on partnership, cooperation, and unity.

However, I then questioned my initial query. Could it be that this former corporate giant was actually moving away from its infamous, directive, top-down management style to work practices that valued joint efforts, improved coordination and collaboration, knowledge sharing, and cohesive working relationships? I decided to try to validate the shift toward collaboration and collaborative research in my own projects by canvassing GM's history. For over a century, GM has engaged in various types of ventures to improve its competitiveness. These ventures have been global in orientation; all continue to be active today. What I found in response to my question pleased and surprised me. 
Export

Export was GM's earliest venture strategy. The GM Export Co. was created in 1911 to sell product outside the U.S. Vehicles were 'completely knocked down' and then shipped to wholesale distributors in places such as Europe and the Middle East.

\section{Overseas assembly}

A second strategy involved overseas assembly. GM began opening plants in various countries beginning in 1923. Within five years, plants were opened in 12 other countries; still more plants were added during the 1930s and 1940s. These assembly plants produced product for markets with the capacity for at least 10,000 vehicle sales while the GM Export Co. ended up serving smaller markets.

\section{Acquisition}

Acquisition of manufacturing operations represented a third strategy. GM purchased operations such as Vauxhall Motors Ltd. in the UK and Adam Opel A.G. located in Germany during the 1920s. This strategy was a way for GM to cope with emerging issues overseas (e.g., higher tariffs, preference for European styling).

Little was collaborative about how these three early strategies worked. For example, the GM Export Co. often disregarded customer requests for service and did not stock spare parts routinely. The overseas assembly strategy was established primarily to compete with Ford Motor Co., not to design products with particular customers in mind. Finally, the acquisition strategy was consistent with GM's autonomous tradition of independently-minded unit management.

GM's overseas operations continued to expand through the mid1960s. Soon after, automotive manufacturers in Europe and Japan began challenging GM's dominance. GM faced increasing government regulation, particularly with respect to vehicle safety, and found its relationship with the United Auto Workers Union (UAW) acrimonious and costly. Outside the U.S., many governments required automotive manufacturers to hire more local employees and abide by local content laws in which a higher proportion of the raw materials had to be local.

\section{Joint venture}

The 1970s represented a turning point in the way GM functioned. GM entered the arena of the joint venture in which a separate organizational and legal entity is created from the resources of at least two companies. 
This new unit operates independently of the parent firms and relies on the principles of partnering - including a desire to achieve common goals, a willingness to negotiate and reach consensus, and an ability to work together. New United Motor Manufacturing Inc. (NUMMI) was one of GM's most notable joint ventures because it involved a key competitor Toyota Motor Corporation. The NUMMI plant was managed by the Japanese with a UAW workforce and some participation by GM salaried employees and executives. Although this joint venture was terminated as part of GM's bankruptcy, it was an important and highly-visible precursor to many other future partnering arrangements.

\section{Global product program}

GM gained experience in internal partnering with the establishment of global product programs in the mid-1990s. I had the opportunity to study the Delta Small Car Program as it was getting underway in 1996. This program consisted of employees from three globally-distributed GM units who were assigned to work together and produce vehicles that would be sold in different markets. Unfortunately, the matrix structure designed to organize the participants was not successful due to insufficient authority of the program manager and strong employee allegiance to their home units. However, other global programs learned from this experience specifically in terms of how employees were organized and the work carried out - so that global programs have operated increasingly effectively over time.

\section{Strategic alliance}

GM participated in a series of strategic alliances, often with companies in which it had equity. I had an opportunity to study GM's strategic alliance with Isuzu Motors Ltd. beginning in 1998. Its purpose was to share costs, gain economies of scale, and produce a truck that could be sold globally. GM's partnership with Isuzu lasted about 35 years - a tribute, at least in part, to the strong relationship formed between the most senior leaders of both firms.

\section{Collaborative research laboratories}

One other strategy was developed during my GM tenure. GM R\&D created Collaborative Research Labs (CRLs) with twelve universities located around the world. These relationships were different from GM's joint ventures, global product programs, and strategic alliances because GM, not its university partners, provided the funding. The purpose of these CRLs was to bring researchers from GM R\&D and the particular universities together to work on applied problems of interest to both parties. Each side placed a high value on the relationships created among 
small groups of researchers, as well as on their research outcomes. For example, GM benefitted from the universities' cutting-edge knowledge and techniques, while professors and their students had opportunities to work on important automotive issues.

\section{Explaining GM's cultural evolution toward partnering}

These historical data on GM's venture strategies corroborate the collaborative patterns associated with my own research career. They show that GM evolved from a corporate entity with unilateral management control to a firm that experimented with, and then adopted, a partnership orientation in its most recent ventures. Many factors contributed to this cultural shift. First, GM faced rising competition globally, particularly from Japanese automakers. Second, customers expected higher quality, better reliability, and improved durability from GM products. Third, GM's own financial resources were shrinking and, at the same time, the corporation faced new government regulations both at home and abroad. All these conditions created a willingness at GM to improve its options by working in innovative partnering arrangements. Finally, GM's products and processes are now largely global. Consequently, collaboration within the firm and with long-term partners is much easier than in the past.

All of GM's various partnerships since the 1970s have had their own unique character. Collaborations that are vitally important today involve China. GM was eager to enter the Chinese market given its vast potential. It pulled together a team of senior GM leaders of Chinese origin to explore ways of penetrating it. The Chinese government requires a joint venture arrangement for any firm wishing to do business in China. Therefore, the structural aspect of any relationship GM would have there was predetermined.

Fortunately, this team recognized the importance of relationships in Chinese culture. It used its own contacts in China, and due diligence, to identify a joint venture partner. Discussions began with Shanghai Automotive Industry Corporation (SAIC) Group, resulting in the creation of SGM (SAIC - GM) in 1997. A decision was made that the joint venture would produce Buicks because of the positive image that the Chinese held of this brand. The time that the GM team spent in cultivating relationships with SAIC and other key Chinese stakeholders paid off quickly. The first Buick rolled off the line in China in 1998. By 2012, GM had sold 2.8 million vehicles in China, making it GM's largest market. GM's recorded revenue in China that year was $\$ 33.4$ billion. 


\section{Conclusion}

Several lessons for anthropologists can be drawn from this longitudinal examination of research approaches, research project themes, and corporate venture strategies. First, it is possible to document cultural change by analyzing anthropological research within organizational settings - both how it is done and what it has found - as is typical in studies of ethnic groups and communities generally. Moreover, other sources of data can be used to validate the results from such analyses.

Second, knowledge of core cultural themes can be useful in describing and explaining the worldview and behavior observed within an organizational culture. A more detailed understanding of the key cultural obstacles and enablers of organizational-culture change can be revealed through an analysis of these themes. Indeed, themes can be critical heuristic devices in encouraging organizational transformation and learning.

Third, collaboration requires an ability to work with people who have different viewpoints, competencies, and roles. Anthropologists are equipped to understand, assess, and translate across organizational, occupational, and national-culture boundaries, as well as the designeruser and producer-customer interfaces. Applied anthropology programs that emphasize collaborative approaches in their training, especially as part of project work, are likely to be valued by clients and positioned for success. Indeed, collaboration with colleagues, study participants, and sponsors is a necessary characteristic of anthropological work in the corporate sector today.

\section{If You Can't Stand the Heat: The Business of Observing Restaurant Kitchens}

Gary Alan Fine, Northwestern University

It takes a feat of memory to recall that it was over thirty years ago that I began my ethnographic research on restaurants and their cultures. At the time I had conducted research on Little League baseball teams and fantasy role-play gamers, but I hoped to expand from the world of voluntary and casual leisure to the examination of institutions that were concerned with the production of aesthetic and sensory objects.

Ultimately I observed in the kitchens of four restaurants in the Minneapolis-St. Paul area: a gourmet restaurant, a restaurant that catered to business clients, a downtown hotel, and a neighborhood steakhouse. In 
examining restaurants I recognized that I was concerned with locations that were simultaneously small groups with their own local cultures, and also economic organizations in which profit was required for survival. These were sites in which individuals had different amounts and forms of power, and in which there existed several competing models that characterized the work (Fine 1996, 2009).

Of course these were not just any work organizations, but specifically organizations that were tight and loud and hot, filled with sensory challenges. Every field site has its own peculiarities, details that become part of the ethnographic story. I have long treasured a quotation from Paul Stoller describing his research among the Songhay in Niger in his Taste of Ethnographic Things. Stoller (1989: 4) writes elegantly, 'Africa assailed my senses. I smelled and tasted ethnographic things and was both repelled by and attracted to a new spectrum of odors, flavors, sights, and sounds.' In a small way Minnesota restaurants have similar effects, creating a buzzing, booming, smelly confusion, but also hopefully for the managers an efficient and profitable confusion.

Observers of any work scene soon realize that workers, no matter if they treasure their work, do not show up by their choice alone. There are schedules and demands that are placed upon them. Bosses need workers at particular times and on a regular timetable. Employees are controlled through a hierarchical organization that has the power - a power that I have seen used - to terminate the relationship if those with decisional power are unsatisfied with the performance or the profit.

Because these spaces are not public arenas, access is provided through the generosity of management, often through some delicate negotiation of what can be seen and when. One depends on the kindness of management. Gaining the blessing of bosses, I had a burden of trust to overcome, as do many other observers of business sites. Workers needed to know, in the pungent words of Howard Becker (1967), 'whose side was I on?' Of course, the true answer was that I was on the side of the academy, of social science, of my own bosses, but I had to persuade both management and workers that I was on their side as well. The question for whom the observer observes is a salient issue, but often it becomes muted as it is clear that no bad outcomes result, at least in the short run.

The clearest expression of this sentiment was found in the hotel kitchen that I studied, part of a hotel chain that operated under explicit, external corporate control. One day early in my time in the hotel kitchen, one of the kitchen workers, noting my notepad, asked me, quite reasonably, if I was conducting a time-management study. More often this tension between being a friend and being a spy or 'fink' emerged in the context of joking. Ostensibly this was friendly banter, but there was an underlying sense of concern. For instance, at the high-end, creative restaurant at which I observed, Davis, a server, jokes to me, asking, 'Who do you really work for? What hotel chain do you really work for?' Diane, a 
cook, suggests that I was a reporter for the National Enquirer, hoping to dig up dirt on the restaurant industry. On another occasion at the continental restaurant, the head chef, Paul, raises the same anxiety in suggesting that I am a spy, adding that 'he's watching to make sure we work.' Similar remarks were made in my presence during my study of three meteorological offices of the National Weather Service, where it was suggested that my presence was related to the work of the office of Inspector General (Fine 2007).

This suspicion became salient in those cases in which minor deviance occurred in my presence. This was particularly evident with lower-status employees, who feared my power over their careers. For instance, one pantry worker noticed that I was watching when she ate a piece of roast beef that had been trimmed. She giggles and asks nervously, 'Are you going to put this in your book?' Later a dishwasher eats some of the beef and jokes, 'Which part will we steal today?' The workers hope that I will legitimate their deviance, or even participate in it, which, of course, I do. These employees wish that I will place myself on their side as a true, if limited, member of their group, embracing its underside. At the steakhouse cooks received beers from the bar, and I did on occasion as well. Once a waitress informed the cooks that I was watching them drink and one of the cooks responded, 'He's on our side. He's exposing the scandals of cooking.' I was touched by the remark.

Of course, the reality was that there were moments in which forces of control ensnared me. Twice I was asked not to observe, both times during the first days of my research. In one case the restaurant was scheduled to be featured on a local television show, and viewers were informed that they would receive a reduced price on steak that weekend. The manager thought that the restaurant would be too crowded and I might be in the way. After I had been present for a few weeks, I observed on equally busy nights. At the continental restaurant, I was asked to skip a day when a server was being trained by watching the kitchen. Again, later in the research, I was present when another server was given the same training. At first, organizations, particularly those with power hierarchies, may be sceptical of outsiders, but with enough goodwill, outsiders can turn into honorary insiders.

A final point to consider in observing organizations is that those who are in control and those who hope to have the organization succeed may wish to have the observer's perspective, often for good causes, even if the consequences can upset the order of things. Throughout my research I was careful not to provide information to chefs or managers about my observations of particular workers and was careful about not being too specific about conclusions that might improve the kitchen. I would never mention food that fell on the floor was quickly washed, reheated, and then served to customers. Still less would I mention the food that was thrown around the kitchen or knives tossed in momentary 
anger. Still, these gatekeepers had my ear when they wished and would learn my general reactions. Even though I have no reason to believe that my comments had any doleful consequences, it is reasonable that workers would worry about what I knew and what I might report. The reality that businesses are organized with power imbalances makes them tricky sites for those who wish to observe their operation without being forced to take sides.

In a previous discussion (Fine 2003), I have argued that observers should strive for what I termed 'peopled' ethnography. By this I mean that while producing theory and not merely descriptive accounts, ethnographers should never lose sight that it is the local, empirical particulars of the group being observed that constitute the research. Theory alone does not make ethnography persuasive. Even if one examines a large organization (and restaurants typically are microscopic organizations), one is examining a set of small groups that negotiate shared problems and constitute a bounded network of these groups. Businesses with their structured hierarchies and their organizational charts exemplify how social systems are constituted by networks of tightknit social relations. The ethnographer who wanders into this field must quickly recognize how that network operates and must recognize, as I did in my smaller organizations, that each relationship one makes and each group with which one has contact is viewed carefully and cautiously by other workers and other groups that see their own position as potentially vulnerable.

I titled this essay by using a phrase that links both to cuisine and to politics, and perhaps that is a properly bifurcated metaphor. Ethnographers must be brave in their observations. They must recognize that while informants are often friendly, it is not only their hearts and arms that are open, but their eyes and ears as well. Ethnographers may face cold informants or hot environs, and both matter in the kitchen, on the shop floor, and within an office.

\section{References}

Howard S. Becker. 1967. 'Whose Side Are We On?' Social Problems 14: 239-47.

Gary Alan Fine. 1996. 'Justifying Work: Occupational Rhetorics as Resources in Restaurant Kitchens.' Administrative Science Quarterly 41: 90-115.

Gary Alan Fine. 2003. 'Toward a Peopled Ethnography: Developing Theory from Group Life.' Ethnography 4:4 1-60.

Gary Alan Fine. 2007. Authors of the Storm: Meteorology and the Culture of Prediction. Chicago: University of Chicago Press.

Gary Alan Fine. 2009. Kitchens: The Culture of Restaurant Work. Revised 
Edition. Berkeley: University of California Press.

Paul Stoller. 1989. The Taste of Ethnographic Things. Philadelphia:

University of Pennsylvania Press.

\section{Doing 'Business Anthropology'}

Katarina Graffman, Inculture

When faced with the task of writing a piece about business anthropology methods, I immediately recognized the challenge in giving a short but fair picture of what it means to be a 'business anthropologist'. What follows is my best response to that challenge.

Seven years ago I founded my company Inculture, enthusiastic but still in doubt about being able to make a living as an anthropologist outside academia - especially without compromising anthropological theory and method - and so enter into ordinary market research, even if a little bit disguised as such! A professor advised me that I had better not mention that I was an anthropologist: 'it will most likely be easier for you to thrive in business by labelling your work as expertise in media and consumer studies'. When I asked why, I learned that 'out there' - meaning the world outside academia - the notion of culture was poorly defined and thus regarded as fuzzy: 'they want facts and figures'.

This advice made me defiant: would the notion of anthropology, my choice of priority subject area, really be more repelling than inviting 'out there'? Consequently, instead of being deterred, I became more determined than ever to emphasis the fact that I am a cultural anthropologist and that the company Inculture is an anthropological consultancy firm, which would always pursue anthropological skills and expertise and defend the importance of these, regardless of client or project.

After having read 'Opinions: What business anthropology is, what it might become... and what, perhaps, it should not be' in the Journal of Business Anthropology, my confusion increased rather than the opposite. I should perhaps be slightly apologetic about being blunt, but I prefer honest criticism. The opinions presented in this issue of the $J B A$ are formulated in a very academic way, and 'business anthropology' itself is defined more as an open question than a proper suggestion. The result is confusion. It does not have to be more complicated than: anthropology, 
both as a theory and as a method, offers a holistic understanding of human action in a society increasingly dominated by marketing and branding. Or, as Ulf Hannerz (2012:254) writes in one of the opinions: 'I see anthropology as a study of all human life in which business these days plays a very central role.'

As I see it, the most challenging tasks of business anthropology are the following:

1. Convincing the client about the aim and importance of anthropology: what can be achieved?

2. Customizing the method for the actual project;

3. Presenting the result in a way which is relevant to business and makes sense to the client.

\section{Convincing the client about the aim and importance of anthropology: what can be achieved?}

One of the most difficult tasks for Inculture has actually been to market anthropological knowledge and its benefits. In this sense, I could agree with the professor mentioned above, 'culture' has become a buzz-word which has a variety of connotations and the conception of anthropology itself is limited. It thus comes as no surprise that these notions pose a problem for most clients, and that the ability to explain why anthropology would make a difference from a business point of view has to be improved. Anthropologists must develop this competence further, as well as how to better communicate their theoretical and methodological professionalism and explain its relevance for business development. Moreover, ethnographic methods and anthropological analyses must be customized to clients' demands and from the start account for commercial relevance. Anthropologists have to extend their area of knowledge to include cognitive science and business administration with emphasis on product development, marketing strategy, consumer theory and communication.

This is, of course, two-edged: to understand and apply knowledge from other disciplines, while also embedding oneself in different business environments without losing the anthropological focus. I have for some years been heading a course in cultural analysis for students learning copywriting and art direction at the most reputable school for communication studies in Sweden. Anthropological knowledge is slowly making its way into advertising and will in the long term both change the way culture is understood in that business and lead to an increased demand for anthropologists. When anthropological theory develops to include knowledge which is clearly relevant for the client's business, it makes real sense and may result in the company manifestly improving its competence to include strategic cultural judgments in their activities (see further Graffman \& Börjesson 2011). 


\section{Customize the method for the actual project.}

If we succeed in convincing a client to use anthropology to enhance knowledge and understanding, and thus enable the formulation of a successful business strategy, the next phase is to decide how this should actually be done. I have so far been trusted to design projects fairly independently, probably due to my recognized experience as an anthropologists, but also as a result of the subject area still being a 'white space' for most clients. All projects are different and each individual project demands full attention to the choice of methods: participant observation, long interviews, ethnography, mapping, and so on. As a business anthropologist you need to be creative when it comes to methods and analysis. Every new assignment is a true challenge and contributes to the ongoing development of methods. All projects have to be anchored in reality rather than in theory, and driven forward by intelligently interpreted facts derived from observations and hearings: what is said and what is actually done. As anthropologists we do not deliver the answers the client presupposes or, even worse, takes for granted. Our professionalism is about being able to create an allencompassing picture of humans' ways of acting - a picture which distinguishes between short lived trends, or ways of living, and long lived human needs, or ways of being.

The applied method does not always have to include ethnography, even if Inculture, more often than not, realizes its importance and makes it part of the project plan. However, it is important to emphasize that fieldwork and participant observation is not always required. Sometimes it is the 'anthropological eye' that is needed: to be a cultural advisor and also to apply one's expertise to already existing facts. New knowledge is gained by combining existing knowledge.

\section{Present the result in a way which is relevant to business and makes sense to the client.}

Most of us are aware that we cannot formulate a consultant

recommendation as a traditional academic report; no one will understand and/or have the time to interpret the text. For those of us brought up in an academic tradition, it is very difficult to change the way we present our research and findings. This became very clear when I was working with an English client and entrusted to understand and define Mauritian culture. The client explained clearly that it was not helped by my academic theorizations and formulations and that the quality of my work was brought down by the fact that I did not trust myself to make clear recommendations and come up with concrete suggestions. As an academic, of course, you are never supposed to do this but to leave the field open for alternative interpretations. The client insisted: 'We wanted 
your competence as an anthropologist and need to know what you think as such. You are the expert; we are not'.

When working in business, you must learn to make the most plausible conclusion whilst taking into account the facts that are present. Not even doctors are always sure when making diagnoses: they use their expertise to make intelligent guesses about the illness you are most likely to have and how best it should be treated. Leaving the patient with the possibility of having a number of potential illnesses, and consequently the choice of a range of different treatments, would quickly undermine the doctor's reputation as a professional.

Grant McCracken (2009) suggests that every company in the future will need a Chief Culture Officer, someone who carries the anthropological way of thinking into the heart of the company and makes it part of its strategic thinking. Maybe this is not imminent, but hopefully anthropological knowledge and theories will in the future be regarded as of strategic importance for business rather than merely as another tool for market research.

Anthropology matters as it can make a difference when judging how matters matter to human beings.

\section{References}

Graffman, Katarina \& Kristina Börjesson 2011. "We are looking forward to some cool quotes!' Perspectives on applied ethnography'. Ethnologia Europaea 41(1): 96-103.

Hannerz, Ulf 2012. 'Opinions: What business anthropology is, what it might become... and what, perhaps, it should not be'. Journal of Business Anthropology 1(2): 254-256.

McCracken, Grant 2009. Chief Culture Officer. How to Create a Living Breathing Corporation. New York: Basic Books.

\section{Business Ethnography}

Stephanie A. Krawinkler, University of Vienna

As a young researcher who only recently finished her doctoral dissertation, I feel both honoured and hesitant about sharing my encounter with business ethnography with colleagues and readers who 
have had far more experience than I. However, I will go ahead and write about my research on trust at a company that I will call Wire Inc. focusing in particular on insights attained through trying to gain access to and information about this company, as well as the mix of methods that I then used there. In addition, I will give a short outline of some of the particularities of engaging in business (as opposed to some other kind of) ethnography.

Born in Austria, I studied International Business Management at the University of Applied Sciences in Eisenstadt, and later also received a Master in Social and Cultural Anthropology, from the University of Vienna. In addition, I was trained in Group Dynamics and Organizational Development at the Alpen-Adria-Universität Klagenfurt, and have worked as a business consultant and an in-house consultant. Since 2006, I have been engaged in organizational focused anthropology, a subdivision of business anthropology.

As I see it, an ethnographic approach can in general help the anthropologist work out who has what kinds of tacit knowledge in an organization - tacit knowledge that, once uncovered, can be of help in the process of reengineering, mergers, and conflict solving. It provides a snapshot of an organizational culture and allows us to develop measures that really fit the company and so, potentially, have a higher rate of being successful. In the following case, however, I did not have a change mandate of this kind, since I was conducting academic research.

\section{Wire Inc.}

As part of my doctoral research I focused on understanding emic perspective(s) in the matter of trust. To accomplish this research, I spent five months over a period of one and a half years as a participant observer in a medium-sized Austrian company called Wire Inc. ${ }^{1}$

Wire Inc. is a family-owned company with a long tradition in offering electrician services. In 2011, one in four employees in the industrial sector in Austria was working for a medium-sized company like Wire Inc. so that it is rather typical of such companies. Located $200 \mathrm{~km}$ from Vienna, it had many out-of-office processes. My choice of this company was partly based on the fact that it was easier to approach an owner in my home country, while its regional distance from Vienna meant it was easier to shift roles and provide time frames for the research, which contributed to efficiency.

Wire Inc. mainly operates in the business-to-business (B-2-B) sector. It went through financially difficult times at the beginning of this millennium and has been undergoing a range of restructuring processes since. At the time I entered as a researcher, the company employed 139

1 This research was partially funded by the University of Vienna. 
people and was strongly male dominated (only ten women were employed at that time). The official structure was a rather flat one and work was organized in projects with varied time-frames from a few days to several months. Because it has had trust issues in the past, Wire Inc. was open to this - at least in Austria - new way of interacting with longtime social research.

My ethnographic approach consisted of applying a combination of methods, which included participant observation, person-centered interviews, group discussions, ego-centered social network analysis, informal talks, experiments, analyses of written material produced by the field, video and photo documentation, and writing a field diary.

\section{Gaining access to Wire Inc.}

There was no prior relation between the company and myself before the research project started. As we know from other accounts, gaining access to a company for research is an often difficult process, but it is one of the crucial points affecting the success or failure of any organizationalfocused business anthropology. In this particular case, a work colleague opened the doors to Wire Inc: she recommended me to them and established an initial connection. Since the practice of conducting longterm business ethnography is almost completely absent in Austria, the recommendation was helpful in my getting a foot in at the door. I had two phone calls with the owner: in the first I described the research outline (including the research design and its possible benefit to the company), and in the second, we agreed on a date to meet.

During the meeting I received a detailed company description and tour; the owner, the CEO and I clarified the research design, including optout possibilities for both the company and myself, access arrangement, informing the employees, and publishing rights. The meeting closed with a shared lunch, which was a further opportunity to familiarize with my future informants. We took a few days to think about the proposal and finally all involved agreed on the research, which should conduct ethnography of, and not for, an organization. This implied that I could from a research point of view - define my own research questions, and that I was not going to be financed by the company, which enabled me to avoid having to deliver 'wanted' results.

\section{Connecting with informants...}

Obtaining access to the company on an official level is only a first step towards success. Even though seldom discussed in the business anthropology literature, it is absolutely necessary to build rapport with informants: managers, employees, workers and apprentices, and whoever else is part of your field. In my case this also included temporary 
employees, cooperation partners, customers, and suppliers. In the end it is their willingness to share their knowledge and insights that allows us to gain a holistic multi-perspective view of a company. In my own case, this involved views from all levels of the company's hierarchy, as well as the standpoints of its departments, the perspectives of its partners, clients and suppliers, and other contextual information. During all of this, I had to adapt to different people in different ways to create empathic connections: by adopting different forms of communication, modes of behavior, and dress codes. Even when doing organization-focused research, the ethnographer has to take all these into account since there are subgroups in every company.

Right from the start, I was very transparent about my role and aims. I was quickly referred to as 'our PhD-candidate' by people in Wire Inc. In this respect, we can say that ethnography isn't just a method, for it is shaped by the ethnographer's own character. My informants perceived me as a member of a university who conducted research in a different city from the one I lived in; who was willing to spend weeks and months away from my family and friends; and last, but not least, who was a woman.

In order to be able to carry out this kind of research, my roles shifted during the course of the project: from social anthropologist setting up a project, asking and discussing things; to apprentice, who learned how to lay cables and install distribution boxes; to team-member at sport events; and facilitator in workshops. These varying roles helped me to understand the everyday working lives of the people I was studying, to establish relationships of trust with them, and to elicit information from them. In this respect, one should never underestimate the value of attention: usually people perform their tasks and only receive attention and feedback when things go wrong or very well. Hardly ever does anyone take an interest in their everyday practices, beliefs and values, in the way that I did as an ethnographer.

These everyday practices on a person's working environment often remain hidden and, in general, people are so busy carrying out their tasks that they do not have the time to find out about and get to know other peoples' perspectives - something that is true of workers, as well as of managers. As long as the anthropologist manages not to be regarded as a spy and reliably shows that she isn't going to rat on someone, this opens up an interesting field of information. This is where being an anthropologist comes into play. I was a free element in the company, and experiencing some of the work tasks and the work environment (cold winters, hot summers, heights, and so on) gave me a multi-layer level of understanding. Hanging out in public spaces within the organization, spending time with people at all levels of the hierarchy and in all departments, and collecting information on similar topics from various different perspectives, gave me a holistic view of the company.

This material could be aggregated at a meta-level as it described 
small particularities. Part of the result was the explication of implicit knowledge - something that can be especially problematic if someone leaves the company and the knowledge gets lost.

\section{Methods applied}

So what exactly did I do at Wire Inc.?

Participant observation was a vital part of my path of understanding Wire Inc. There are four quadrants of information in this (Jordan \& Dalal, 2006: 366): saying, doing, thinking and feeling. The first quadrant is accessible through interviews, focus groups and group discussions, as well as through informal talks. But the more 'subtle, tacit, implicit, and context dependent' (ibid.) information of the other three quadrants lies beyond spoken information, so that ethnographic approaches are a means to elicit these by 'digging deeper under the surface'. In this case my participant observation ranged from periods of full observation to full participation. The latter was one of the keys to my finally being invited to the company's informal events that were valuable sources for me to comprehend communication and trust structures at Wire Inc. All this needed time and a willingness to engage with people, hence carefully sharing precious time.

Especially in the beginning, I shadowed a sample of people through a day, or a project team over a couple of days. Generally, we finished with a person-centered interview towards the end to clarify observations allowing space and time for informants to share their perceptions of what was going on. Another means of data collection was through group discussions, which provided the space to discuss topics like trust (and confront different opinions people had), that are usually implicit in daily actions but generally left outside the topics of ordinary business meetings, unless there happens to be a particular issue to be resolved.

After being in the field for a couple of months, I started conducting ego-centered network analysis interviews on the theme of trust: collecting sensitive data on trust relationships between employees in the company. Obtaining this information only succeeded because the people concerned thought my way of handling data was trustworthy.

Informal talks went along with participant observation: whenever I wasn't disturbing the workflow, I used to engage with informants. Notably, car rides as well as company events, proved to be valuable moments of informal interaction to enhance my understanding of what was going on at Wire Inc.

The company also provided me with broad access to its data and documentation, and I was also allowed to take photos and make my own video recordings. These audiovisuals were helpful when it came to my analysis of fieldwork data (transcribing and reanalyzing earlier events), 
as well as when making presentations and discussions of results both within the company and in academia. Last but not least, I kept a research diary.

All in all, the methods applied focused on seeing:

'Seeing, as opposed to looking, embraces the whole body, neither vision alone nor disparate senses. The whole body is the means to understand and resonate with the world. The body becomes the memory and is not so easily separated from the mind, as in the Descartian tradition.'

(Okely, 2001: 104)

The method-mix that I adopted was chosen to answer the research questions of this particular project. However, I suspect that different research aims and environments would require a different set of methods.

\section{Particularities of business ethnography}

Being asked to write about ethnographic methods, I feel the need to emphasize that to me ethnography is more than just a technique. As Van Mannen (2006) notes, ethnography is a process as well as a product. Hence, it is as much in the process of data collection as it is in the time spent analyzing the material (and the two often run in parallel). It is also the written product that appears as a monograph - like my own thesis (Krawinkler, 2013) - or as articles. I would like to add that ethnography is a process and a product characterized by a particular type of attitude, so that, so far as I am concerned, 'anthropology is a way of thinking' (Eriksen, 2004: 169) and ethnography is shaped by it.

'Ethnography often runs counter to common knowledge because it requires tapping into what people often take for granted about their work, and thus, do not ordinarily discuss.'

(Jordan \& Dalal, 2006: 368)

The anthropologist, who is trying to figure out how things work, why things are done in a specific way, and what is the meaning of certain artifacts, can act as a refreshing influence in a business organization and, as a result, people employed there often start reflecting on their general surroundings and habits. In other words, she stimulates informants' awareness of their own environment. The anthropologist goes after tacit knowledge, the ideas submerged in underlying structures that can be likened to an iceberg hidden under the surface of the sea. Ethnographic approaches allow us to discover the differences between saying and doing that usually hint at interesting discrepancies.

What, if any, are the particularities of business ethnography? As I mentioned earlier, I believe that ethnography is shaped by an 
anthropological attitude. As Thomas Hylland Eriksen (2001: 4) says:

'A few important defining features of anthropology are nevertheless common to all practitioners of the subject: it is comparative and empirical; its most important method is fieldwork; and it has a truly global focus in that it does not single out one region, or one kind of society, as being more important than others.'

In many aspects, therefore, business ethnography is comparable to any other anthropological subfield research. However, my own experience suggests that the following points also need some consideration: access, language and cultural codes, time, responsibilities of the anthropologist, ethics and data presentation. Of these, responsibility and data presentation are, to my mind, particularly important.

- Responsibility: There are societies with organizational boundaries that encourage a generally high rate of inter-dependence among their members. As a result, even if you are solely observing, you already have an impact on the field. We need to be aware of this effect and handle this responsibility with care. Everything we do or do not do, say or do not say, is interpreted by our informants, and it has the power to change processes. This can be a wanted effect, if we have been given a change assignment. But, in contrast to more classical fields of anthropology, the power relationship between anthropologist and her field of research is different. Some of the corporations commissioning anthropologists act globally. Anthropologists are indeed 'studying up'.

- Data presentation: Lengthy, detailed ethnographies might be an interesting read for some people, but they usually do not fit well with the fast pace of the business world -neither in terms of the time it takes to produce them, nor of the time needed to read them. On the contrary, the likelihood of reports being looked at, and their contents incorporated into ongoing practice, increases if we use a language and a way of presentation that is familiar to the people addressed. In the research elaborated on above, I provided a PowerPoint-presentation and discussion for the owner and the CEO, and an exhibition of the same results throughout the company for everyone else interested. I also wrote an article for the company's magazine and Wire Inc. received a copy of my scientific ethnography (in other words, my Ph.D. thesis). The management decided to frame the posters from the exhibition and these are still on display in the entry hall of the main building of the company.

Although there is a lot more that could be said (in particular about commissioned research and consulting, on the one hand, and about the uses to which 'ethnography' are put by people who aren't anthropologists, on the other), I have tried here to show why business ethnography is a 
valuable approach to the study of organizations. Making use of the example of Wire Inc., I illustrated some of the difficulties involved in doing such research - in particular, the issues of access and connecting with informants, as well as the mixed methods that I adopted. Hopefully, you have got a taste of what business ethnography conducted by a young graduate student in an out-of-the-way country can be like. And since I appreciate exchange, collaboration, and sharing my experiences, as well as opportunities to gain further new experiences, I look forward to hearing from you at email@stephaniekrawinkler.com

\section{References}

Eriksen, Thomas H., 2001. Small places, large issues: An introduction to social and cultural anthropology. London: Pluto Press.

Eriksen, Thomas H., 2004. What is anthropology? London: Pluto Press.

Jordan, Brigitte and Brinda Dalal, 2006. Persuasive Encounters: Ethnography in the Corporation. Field Methods 18(4): 359-381.

Krawinkler, Stephanie A., 2013. Trust is a choice. Prolegomena of Anthropology of Trust(s). Heidelberg: Carl-Auer-Verlag.

Okely, Judith, 2001. Visualism and Landscape: Looking and Seeing in Normandy. RETN 66(1): 99-120.

Van Maanen, John, 2006. Tales of the field: On writing ethnography. Chicago: Univ. of Chicago Press.

\section{0 on Method}

Maryann McCabe, University of Rochester

Since the time of our founding participant observer Malinowski, there has been a radical change in approach to anthropological research, with increasing focus on the social production of knowledge. Compared to earlier days of participant observation when the anthropologist was considered an objective observer or authority, today the ethnographic fieldworker is thought of as engaged in a project of co-construction or cocreation (Oliveira 2012). Two streams of thought have influenced this shift in perspective on the anthropological self, the other, and the process that transpires between them. One is the postcolonial moment (Clifford 
1986); the other is the more recent collaborative turn (Thrift 2002). While anthropologists across the discipline have been active in building both streams of thought, business anthropologists stand in the forefront because of the need for collaboration in praxis. This essay explores the shift in methodological approach from objectivity to subjectivity and epistemological issues of producing knowledge. It argues that, as a result of the postcolonial moment and the collaborative turn, anthropologists live and work in fluid liminal space where they negotiate different worlds of meaning.

Business anthropologists find themselves continually moving across boundaries as they conduct research in and with companies. These boundaries include business units within a corporation, functional departments at advertising agencies, segments of the consumer population, and so forth. Working with engineers, psychologists, and designers, for example, involves an ongoing dialogue across boundaries that keep the anthropologist in a more constant liminal state than previously theorized. From its earliest conception by Arnold van Gennep (1960), through key works by Victor Turner $(1967,1969)$, liminality has been conceived as a 'betwixt and between' transitory stage through which the social person or community passes. Business anthropologists move in such liminal space, regularly carrying out projects and communicating with people inhabiting different worlds of meaning. In this essay, I rely on case situations from my consulting practice to examine liminality from a perspective of fluidity and movement in the postcolonial and collaborative environment of conducting participant observation.

\section{Participant observation as performance}

In his penultimate book, Geertz (2000) pens a fieldwork biography and muses about his experiences as participant observer in Java, Bali and Morocco. Writing about his first experience studying Javanese religion, he refers to participant observation as 'learning how to live with the natives' in a bemused way which foregrounds the performative nature of the method. As he writes, 'what had begun as a survey of (this has to be in quotes) "the role of ritual and belief in society," a sort of comparative mechanics, changed as the plot thickened and I was caught up in it, into a study of a particular instance of meaning-making and the complexities that attended it (2000:15). Participant observation is performative insofar as the anthropologist is an instrument of experience, perception and interpretation. Thus, compared to the conception of the participant observer in the earlier Malinowskian time as objective authority, Geertz points to reflexivity in gaining partial truths about cultural beliefs and practices.

Similarly, as the notion of participant observer changed, the idea of the native's role in the research process has shifted from passive to active. This is expressed, for instance, in the approach to interviewing where the 
person is no longer considered a vessel of answers, a repository of knowledge, but a participant in the interaction (Holstein and Gubrium 1995). The native becomes a producer of meaning who develops a narrative in concert with the ethnographer.

A marketing research project in the cruise industry highlights this interactive relationship between anthropologist and native in the field setting. For a cruise company, I conducted participant observation on two cruises, each on a different competitor line, in an effort to understand the meaning of a cruise for people who enjoy taking cruises. The company owned several lines and wanted to develop brand architecture and delineate a positioning for each line in its portfolio. A colleague, anthropologist John F. Sherry, Jr., took cruises on the company's own lines. As participant observers, we took note of our own reactions to the built environment and to observations of and encounters with other passengers.

One of my experiences involved participating in the formation of an onboard group of eight people seated at the same dining table, including sisters who were amateur singers in their hometowns. They cajoled the rest of us into singing songs together when exiting the dining room. As a group, we engaged other people in song. The group of eight formed a relationship and gathered to share activities on the ship at other times of the day. After the cruise ended, the relationship continued for a while through email contact. Creating a sense of belonging is a common onboard experience, one of the many meanings of taking a cruise. People who develop bonds onboard may pursue friendship and even become cruise mates in the future. By participating in the group of eight, I coconstructed the meaning of community and learned about this perhaps ephemeral but important kind of social relationship occurring on cruises.

\section{The postcolonial moment and power}

Post-colonial thinking about participant observation and writing cultural accounts emphasizes historical context and relations of power between the native and the anthropologist. As Clifford (1986:9) says, 'ethnographic work has indeed been enmeshed in a world of enduring and changing power inequalities, and it continues to be implicated. It enacts power relations'. As a result, recognizing the positionality of researcher and other persons in the ethnographic encounter becomes part of the analytic grist. This aspect of reflexivity, making clear how the power in the relationship affects knowledge gained, is a tool in elucidating the worlds of meaning inhabited by the anthropologist and the research participants. Reflexive introspection about relations of power continues to be an important part of cultural analysis long after the encounter has ended (Olsen 2012).

A study of champagne practices for a U.S. wine importer shows how 
awareness of power relations enters marketing research analysis. For this project, I conducted participant observation in wine stores and at wine tasting events, and interviewed champagne aficionados in their homes and accompanied them on shopping trips. During the interviews, it became apparent that the research participants expected me to be knowledgeable about champagne. They assumed I would have answers to their questions about the complex industry of champagne. Frustration was evident when I did not have answers either because in fact I did not know the answer or was feigning ignorance as a tool to explore their practices. The expectation that I would be an expert, and therefore in a position of power, and the disappointment when I did not give evidence of this power, revealed the importance to aficionados of gaining greater competence as champagne connoisseurs. By analyzing emotional aspects of the interactions, I learned that champagne signifies not only celebration but also enjoyment of one's knowledge of champagne production and consumption.

\section{The collaborative turn and social process}

Nigel Thrift (2002) describes the current state of Western capitalism as a rule of emergency because of the time horizon on short-term financial performance and speed-up in the conduct of business, including the need to react quickly to competitors, suppliers and customers. Keys to success in this faster-paced environment are creativity, innovation, collaboration and knowledge exchange. Business anthropology partakes of this environment by collaborating with various partners to affect organizational change, product design and marketing strategy. Working in and with companies, business anthropologists adapt and develop research methods to gain insight as quickly as possible. We usually employ multiple methods, famously called a triangulation of methods, to reach deep cultural understanding of business issues at hand.

In a research project on creativity and cooking for a food company (McCabe and Malefyt 2013), anthropologist Timothy de Waal Malefyt and I were concerned with understanding how US women think about meal preparation and construct dinner on a daily basis for their families. We conducted in-home interviews, which involved conversations using a loosely structured interview guide, tours of the kitchen, and observation of mothers cooking a meal for the family. In addition, we went on brief food shopping excursions with each respondent. Prior to the in-home interviews, we had asked our research participants to keep in-depth journals of their daily thoughts and feelings around meal planning over the course of a week and to make a collage of their favorite meals.

Combining these methods provided a fuller picture of dinner issues than each single method alone, but the participant observation of cooking a meal produced a key insight. The observation uncovered how women improvise in the kitchen. 
When asked about what they cook for dinner, mothers responded that they had a repertoire of meals their families enjoyed and occasionally tried new dishes. What became apparent as mothers cooked and talked with us about their actions was how they altered ingredients, less of this, more of that, substituting one thing for another, based on knowing the likes and dislikes of each person in the household. These slight changes, such as substituting cinnamon for cumin, were creative adaptions to recipes that were not articulated during the more formal part of the inhome interviews. Only during the cooking process did improvisation come to light. Of course anthropologists are aware that cultural assumptions underlying people's practices often lie hidden. As McCracken (1988:23) writes, 'most respondents have difficulty giving a full account of what they believe and what they do. Long ago, their beliefs became assumptions and their actions became habits. Both are now almost completely submerged beneath the surface of consciousness'. In this case, what provided insight was the social process of observing and conversing with women while they cooked. Letting them articulate how they improvise to satisfy the tastes of everyone in the family revealed that preparing dinners the whole family will enjoy together was - and is - a way of creating family life. We learned that creativity in everyday life begins with the familiar and makes small adjustments rather than being a novel and complete departure from something existent.

\section{Ethnography co-created with client participation}

For business anthropologists, another aspect of co-creation in fieldwork is having clients join encounters with research participants. It has become commonplace in marketing research to invite people from the sponsoring company and advertising agency to accompany us for in-home interviews and group discussions. Clients appreciate this because it gives them an opportunity to speak with consumers and see the context of their everyday lives. As business anthropologists, we are happy when members of the client team come to the field, because interaction with them usually gives us a larger grasp of the business issues and often produces ethnographic insight. I remember, for example, a breakthrough moment conducting research for a pet food brand. One morning I was having breakfast with the client and as we discussed the in-home interviews under way, a bolt of lightning struck us both. We realized that research participants were talking about pets as social connectors in the family and that this would provide a new and unique positioning idea for the brand. The conversation stimulated analytic thinking about the meaning of pets and corporate strategy and communications (McCabe 2014).

Having clients participate in the ethnographic process, however, introduces a layer of complexity for business anthropologists. It puts the anthropologist in liminal space and time when he or she is conducting an interview, trying to gain the respondent's perspective and attempting to 
complete the interview in an allotted time frame, while at the same time, entertaining the client view and allowing the client to ask questions and pursue lines of corporate interest. At times respondents recognize the expert authority of the client and engage in extended conversation with the client about the company's products and their use of them. This may require the anthropologist to manage the interview in order to retain rapport with the respondent and facilitate the social production of knowledge. In these situations, business anthropologists work in tripartite liminality as they move between the spaces of anthropological thought, consumer practices and client objectives.

\section{Conclusion}

Anthropological research has taken a 360 degree turn in approach from objectivity to subjectivity since the beginning of fieldwork in the discipline. Shifting from the participant observer as objective authority, ethnography has changed to consider reflexivity and positionality between anthropologist and research participant in crafting a representation of people. Business anthropology reflects a current view of participant observation as co-constructed or co-created experience. This raises a postmodern question about the validity of different cultural accounts or, as Clifford (1986) phrases it, whether one cultural account is as good as another. The issue surfaces for business anthropologists, for example, when marketing research results differ from market segmentations held by clients, or when collaborators in design and organization change studies have different professional backgrounds. In these situations, blueprints for corporate action typically emerge as negotiated solutions among participants (Malefyt 2003, Denny 2013).

The 360 degree change in approach to anthropological research shows how elastic and powerful a method participant observation remains. Elasticity has enhanced the power of the method through incorporation of concepts of reflexivity, positionality, representation and negotiation. This reconfiguration of participant observation enriches our ability to understand cultural practices in the world. As business anthropologists embark on projects and go from one project to another, they move in liminal space and time, intermittently working with clients, research participants, and other colleagues who have different concepts, languages, and worldviews. In this fluid space, they listen to multiple voices, gain insider views, and communicate across boundaries. Business anthropologists live in a perennial space of liminality where meanings are grasped and often negotiated.

\section{References}

Clifford, James. 1986. Introduction: Partial truths. In Writing culture: The poetics and politics of ethnography. James Clifford and George E. Marcus, 
eds. Berkeley: University of California Press, 1-26.

Denny, Rita. 2013. The cry for practicality. In Advancing ethnography in corporate environments: Challenges and opportunities. Brigitte. Jordan, ed. Walnut Creek: Left Coast Press, 136-150.

Geertz, Clifford. 2000. Available light: Anthropological reflections on philosophical topics. Princeton: Princeton University Press.

Holstein, James A. and Jaber F. Gubrium. 1995. The active interview. Thousand Oaks: Sage.

Malefyt, Timothy deWaal. 2003. Models, metaphors and client relations: The negotiated meanings of advertising. In Advertising Cultures. Timothy deWaal Malefyt and Brian Moeran, eds. Oxford: Berg, 139-164.

McCabe,Maryann. 2014 (forthcoming). Pets and configuring family, kinship and natural cosmology. In Sourcebook in business anthropology, Rita M. Denny and Patricia L. Sunderland, eds. Walnut Creek: Left Coast Press.

McCabe, Maryann and Timothy deWaal Malefyt. 2013. Creativity and cooking: Motherhood, agency and social change in everyday life. Journal of Consumer Culture. Online First, June 25, 2013. doi:10.1177/1469540513493202.

McCracken, Grant. 1988. The long interview. Thousand Oaks: Sage.

Oliveira, Pedro. 2012. Ethnography and co-creation in a Portuguese consultancy: Wine branding research as an example. Journal of Business Anthropology 1(2): 197-217.

Olsen, Barbara. 2012. Reflexive introspection on sharing gifts and shaping stories. Journal of Business Research 65: 467-474.

Thrift, Nigel. 2002. Performing cultures in the new economy. In Cultural economy: Cultural analysis and commercial life. Paul du Gay and Michael Pryke, eds. London: Sage, 201-233.

Turner, Victor W. 1967. The forest of symbols: Aspects of Ndembu ritual. Ithaca: Cornell University Press.

Turner, Victor 1969. The ritual process: Structure and anti-structure. Chicago: Aldine.

Van Gennep, Arnold. 1960. The rites of passage. Monika B. Vizedom and Gavrielle L. Caffee, trans. Chicago: University of California Press. 


\title{
For Opinions: Ethnographic Methods in the Study of Business
}

\author{
Patricia Sunderland and Rita Denny, Practica Group, LLC
}

When Brian asked us for an opinion piece about ethnographic methods in the study of business, he asked for one 'especially relating to your work with consumers' and added that he thought it would be best 'if it were based on personal experiences and included reflections on what might have been improved, how business ethnographers compare with 'ordinary' ethnographers in the field, and so on and so forth.'

As anthropologists who work in the consumer research space of anthropology in, on, and for businesses it would be easy, indeed it would be predictable, to lament the thinness of ethnographic work that takes place within corporate consumer research. We could, in fact, speak of the utter predictability and commodification of ethnography within this realm. In commercial consumer research 'an ethnography' has been rendered to a three to four hour at-home encounter with a pre-recruited (individual) respondent, an encounter that almost always includes a sit down interview component, a home tour including some sort of demonstration, a shop-along portion if conceivably relevant, and invariably something like collage homework completed before the researchers arrive. Almost all consumer research firms that offer ethnographic research - at least in the United States - offer some version of this, including ours. Design firms also routinely offer ethnographic research.

It would also be somewhat easy and predictable to lament the relative demise of queries for ethnographic work within corporate consumer research circles in the wake of Big Data. There is no question again, in the United States at least - that Big Data have operated not just as a surging wave, but rather as what feels like the destructive recurrent tidal power of quantitative frameworks to be constituted as the way of knowing, the way of predicting, and thus for corporations, embraced as the way to assure future commercial success.

Many anthropologists who work in consumer research in the United States do so as freelancers and/or as part of small boutique firms. We all have felt the impact of the incursion of digital and digitallycollected Big Data, along with the commodification and ubiquity of the ethnographic offer outlined above. Together with the economic downturn in 2009, in which corporations made severe cuts and process changes in their ways of commissioning consumer research, it has been dare we say it - a tsunami. Many small firms have gone out of business, freelancers have not found enough work to sustain themselves, and many anthropologists have joined large firms, the numbers game, or re-joined academia. Without question we have also pondered and been pulled by 
these possibilities. And we could have written about this, given Brian's cue that personal experience should be the muse.

But what we decided to write about here was actually inspired by a fieldwork experience that occurred shortly after we received Brian's request. At that time, we ${ }^{2}$ were involved in on-site (but not in-home) fieldwork for a brand that offered experiential entertainment. Our client, as is often the case, was in the field with us, and he wanted to take part in at least the first phase of the research - to see what was going on and, in this case, also to broker our entrée. He was a client with whom our past projects had been a success; nonetheless he was nervous, there was a lot riding on the outcome of this particular research. As a result, he seemed not able to keep himself from offering tips. He told us to please attend to language, to really listen and pay attention to how people said things. He wanted to be sure that we would attend to the kinds of language people actually used in that setting, as well as the language they spontaneously used to describe that setting. As he said, he wanted to be sure we found out 'the lexicon.' He also told us at the same time to attend to small details, to really look at what people were doing, not just to listen to what they said. When we related some of our early analytic thoughts and observations on the morning following the first day of research, he exhorted us to please 'ladder up and down,' to be sure to 'push up and down.' He wanted us to be sure to note how these observations and points and any others we would make were instantiated in the smallest ways or actions, as well as ladder up to the larger implications and ramifications, specifically the ways this issue tied in with larger sociocultural meanings, phenomena, and the implications thereof. He reminded us throughout to be very context-oriented and specific in our observations and analysis. For example, what time of day and where exactly in the environment was $\mathrm{x}, \mathrm{y}$, or $\mathrm{z}$ happening? What kind of person or persons were involved, a younger or older male or female, and were they alone, or with others and if so how many???? In addition, he told us on a few occasions that if, in the course of the more formal interview encounters we had planned, the conversation veered into what seemed more promising directions, to just jettison the guide and follow these more fruitful avenues that particular participant could help us explore.

As he exhorted these types of reminders and proclamations, we appreciated that, really, he was the perfect client. Everything he said, every tip he gave, were things that we were already reminding ourselves to do. Exactly those kinds of guidelines and hints would be the kinds of things we would undoubtedly try to instil in a student of the ethnographic method. Very likely we would even phrase things similarly, perhaps even using his particular lexicon. If here it would perhaps have also been easy to be mildly annoyed and get wrapped up in thoughts of 'of course, I know to do that,' the more interesting issues to ponder were how he knew all

2 The 'we' in this sentence includes anthropologist Stas Shectman. 
these 'truths' and 'hints' about conducting ethnographic research and what it might imply, socio-culturally, that he did.

Undoubtedly, he knew, in part, about conducting ethnographic fieldwork because of projects he had commissioned with us before. But, for us, his comments suggested a greater appreciation of ethnographic ways of knowing. It spoke to us of a larger cultural current that also resides and resonates in broadcasts of National Public Radio, the pages of The New Yorker, and perhaps even television's relentless reality shows. The tacking back and forth between the micro and macro, the search for the meaning of experience, culture and society as something we should think about as being part of popular American parlance. For the purposes of this particular opinion piece, the socio-cultural implication of all this is that, for anthropological consumer researchers, there is hope.

In the course of this particular project there were other reminders and glimpses of hope. One of the people recruited to participate in the project, one of those people with whom we jettisoned the interview guide, referenced in the interview how he really thought the phenomenon we were discussing cut to the heart of 'civilization' and told us that he had gotten these ideas from a book he'd read by an anthropologist. He promised to email the reference after the interview, which he did. Throughout the time of the analysis and write-up of this project, we worked closely with the client with whom we had been in the field. He exhorted and critiqued on numerous occasions that not enough cultural implications were included. He wanted more explicit ties to the cultural underpinnings of what we were reporting as findings, and he wanted us to call out the ways in which our findings tied to larger socio-cultural trends. At the close of this project, during the final presentation to the corporation, the CEO spoke of how much he appreciated anthropology as a field - as an undergraduate that was where his heart had been. While life had taken him in other directions, he had himself thought of becoming an anthropologist.

So, in essence, what we are writing about is that there is a place - in business and in consumer research - for anthropological casts of mind as well as methods. We can look at the ubiquity and commoditization of ethnography as an offer of consumer research firms, as well as the incorporation of ethnographic approaches within the field of design, not as problems and bad signs, but as signs of a flourishing and effervescence. And, as anthropologists, it is in our purview to take this further and employ ethnographic methods beyond the expected, the predictable, and the commoditized, and one way of doing this is by simply dipping - a little creatively - back into the established anthropological well.

In JBA's Autumn 2012 set of opinion pieces about business anthropology, Moeran (2012: 294) argued in his coda that we must be comparative. In fact, he maintained that this point, his second programmatic statement for business anthropology was 'so obvious it 
shouldn't need saying'. In our own methods we have drawn on anthropology's established value and reliance on the comparative stance to devise some of our most fruitful consumer research projects. For instance, we relied rather directly on the anthropological tradition of using the insight gained from studying other societies as an illuminating lens on one's own, when we suggested to a client that, to explore the terrain of personal space and sensations for the purposes of a new product for the US market, it would be best to do so by exploring personal space and sensation in very different socio-cultural milieus. Research for this project led to fieldwork in Paris and Ho Chi Minh City, along with research in Chicago. ${ }^{3}$ There was no question in our minds - and, after the analysis, also our clients' minds - that the foundation of ideas for potential new products for the United States would not have been nearly as rich, not nearly as intricate, nor nearly as illuminating, were it not for the practical and analytic comparisons that the fieldwork in France and Vietnam afforded.

In a slight twist of the rather literal cross-cultural comparison method, we have also conducted projects where the most illuminating findings were garnered by exploring a phenomenon beyond the domain of the client's place of interest. For instance, we were commissioned to conduct a study that would inform advertising for the Detroit Institute of Arts (DIA) for its 2007 reopening after a major, multi-year renovation. The DIA wanted to attract local residents to the museum. While local residents would attend sporting events in venues not far from the art museum, visit Detroit science museums with their kids, and visit art museums when on vacation in other cities, as a rule they did not visit the DIA, even though it includes one of the premier art collections in the United States. So, the advertising agency (Perich Advertising + Design) and the DIA knew they had a challenge on their hands, and requested an ethnographic study that would inform their own strategic and creative thinking. For this research, rather than visiting any art or other museums with them, we ${ }^{4}$ sought to understand what art and inspiration meant in people's everyday lives. Tapping into these meanings did in fact lead to the ideas that allowed the advertising agency to create ads that got residents to visit their local art museum in relative droves. As a result, the agency's 'Let Yourself Go' campaign 5 itself became something to talk about, including the fact that anthropological research had been the catalyst for conceiving the campaign (Berman 2008). Likewise, a project for the Brooklyn Botanic Garden (BBG), that had at its source BBG's question of how to encourage more visits among diverse ethnic groups living in Brooklyn, was carried out by going not only to the Botanic Garden, but also to the small community plots, backyard gardens, flower

\footnotetext{
${ }^{3}$ For this project, fieldwork included collaboration with anthropologists Christophe Robert, Dominique Desjeux, and Anne-Sophie Boisard.

${ }^{4}$ Anthropologist Robert Moise was an integral part of the 'we' here.

5 To see the campaign go to http://perich.com/case-studies/dia/
} 
boxes, and even beloved 'street trees' of residents. ${ }^{6}$ Understanding those gardens was the key to understanding what the BBG was - and what it could be - for Brooklyn residents.

Beyond this dipping back into anthropology's traditional well, anthropologists and others in consumer research have also found success in utilizing new technologies and modalities with participants, whether in the form of video and audio diaries or online interactions with individuals and groups. With the latter, we have found that participants can be particularly expressive in choosing or taking and then uploading photos that express what they'd like to communicate, as well as then writing about the meanings of those photos. We would also note that fully webbased ethnography, a reading of existing blogs, postings, and opinions, which Scull (2009) has termed webnography, can also be a powerful tool. Filtered through an anthropologically-informed mind, this reading in a new medium is not unlike anthropologists' cultural readings of letters and documents, a respected means of gaining insight to times and places no longer accessible to the face-to-face. Since so much of our current social life does not take place face-to-face, as ethnographers we do need to take part; and again here, even in doing so, we are also dipping into the tried and true.

In the end, with these necessarily short snippets we are suggesting that anthropologists working in consumer research should have hope. We can garner energy from the ethnographic sentiment that lives in the atmosphere, even in the midst of pressured tides of quantitative and economic realities. There are many of us out there, as careful readers of the footnotes may have surmised; even the circumscribed 'we' of this small piece includes many anthropologists, and our firm is only one among many. As anthropologists forge into new territories, we also believe that by leaning into our own training and methods, the anthropological voice will have its place. Ethnography may have become unbound and into, on, and for business, but it's a good thing. Moeran (2012:294) has provided us with a useful list of prepositions that currently can and do link anthropology and business: 'in, on, for or against.' We have been rather liberal in our borrowing of in, on, and for, but 'against' should also be included. If we view the ubiquity of an ethnographic offer among consumer research firms as part of the atmosphere, we can also push against the commodification. As anthropologists we have the ability to do so. We know that the ethnographic method has always encompassed a myriad of approaches, constantly changed as it has faced and lived amidst new social as well as new technological realities, and most importantly, constantly been reanimated and newly enchanted with, by, and through - and yes, also

\footnotetext{
6 The Brooklyn Botanic Garden research was carried out by Practica anthropologists Michael Donovan and Charley Scull, a fuller description of this research can be found in Donovan (2013).
} 
against - theory. So we have not only hope, but also heart.

\section{References}

Berman, Laura. 2008. Clever ads transform DIA into getaway. Detroit Free Press. February 12.

Donovan, Michael. 2013. When ethnography really works. QRCA Views 12(1): 28-34.

Moeran, Brian. 2012. Coda to Opinions: What business anthropology is, what it might become ... and what, perhaps, it should not be. Journal of Business Anthropology 1(2): 290-297.

Scull, Charley. 2009. Market research, webnography, and chronic disease. Paper presented at the $108^{\text {th }}$ American Anthropological Association Annual Meeting, Philadelphia PA. 